\title{
Effect of Matrix Rhythm Therapy in Venous Ulcer Healing: A
}

\section{case report}

\section{Harish Kumar Rajendran.}

Physiotherapist, Head of the department, Sai Healthcare Foundation, Chennai- 600 004, India.

\section{ABSTRACT}

\begin{abstract}
Introduction: Venous Ulcers are due to abnormal vein function. People may inherit a tendency for abnormal vein. Common causes of damaged veins include blood clots, injury, ageing and obesity. This is one of the common problems for professionals who are standing by nature. Symptoms include swelling, aching and tiredness in the legs. Usually a red, irritated skin rash develops into a open wound. Matrix Rhythm Therapy (MaRhyThe) is a recent clinical modality, which works on cell biology and gives good results in pain management and restriction of movements.
\end{abstract}

intervention: Matrix Rhythm Therapy was applied on posterior aspect of leg region extending around the wound are once a week for 8 weeks with treatment duration of 60 minutes.

Result: Pain of the subject after 8 session was 0 at rest and 2 while walking on the basis of VAS. Wound size is length $8 \mathrm{~cm}$ and breadth $7 \mathrm{~cm}$ and $2 \mathrm{~mm}$ dept and categorized as Type A grade 1 which completely healed with healthy scar. The photographic evidence is suggestive considerable healing of venous ulcers are noted between each session of matrix rhythm therapy (MaRhyThe).

Conclusion: Study concludes that Matrix rhythm therapy (MaRhyThe) could be considered as adjunct in wound healing of venous ulcers.

KEY WORDS: Matrix rhythm Therapy, Venous ulcers

Address for correspondence: Harish Kumar Rajendran, Physiotherapist, Head of the department, Sai Healthcare Foundation, Old No 24, New No 49, East Abiramapuram $3^{\text {rd }}$ Street, Mylapore, Chennai- 600 004, India. E-Mail: luzphysio@gmail.com

Access this Article online

Quick Response code

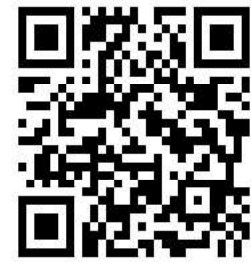

DOI: $10.16965 /$ ijpr.2021.187

\section{Journal Information}

International Journal of Physiotherapy and Research

ISSN (E) 2321-1822 | ISSN (P) 2321-8975

https://www.ijmhr.org/ijpr.html

DOI-Prefix: https://dx.doi.org/10.16965/ijpr

\section{Article Information}

Received: 21 Aug 2021

Peer Review: 21 Aug 2021

Revised: None
Accepted: 05 Oct 2021

Published (O): 11 Oct 2021

Published (P): 11 Oct 2021

\section{INTRODUCTION}

Venous leg ulcers (VLUs) are defined as open lesions between the knee and ankle joint that occur in the presence of venous disease. They are the most common cause of leg ulcers, accounting for $60-80 \%$ of them. The prevalence of VLUs is between $0.18 \%$ to $1 \%$. Over the age of 65 , the prevalence increases to $4 \%$. On an average $33-60 \%$ of these ulcers persist for more than 6 weeks and are therefore referred to as chronic VLUs. Risk factors for development of VLUs include older age, obesity, trauma, immobility, congenital absence of veins, deep vein thrombosis (DVT), phlebitis, and factor $\mathrm{V}$ Leiden mutation. Chronic venous leg ulcer results in reduced mobility, significant financial implications, and poor quality of life. There are no uniform guidelines for assessment and management of this group of conditions, which is reaching epidemic proportions in the prevalence. Prevalence of leg ulceration increases dramatically with age, although ulcers can occur in quite young people and there are records of people suffering with venous ulcers for up to 60 years. 
In venous disease, ulcers are usually located in the gaiter area between the ankle and the calf, often on the medial aspect of the leg. Venous ulcers arise from venous valve incompetence. Valvular incompetence in the deep veins causes the vessels to become distended and stretch to accommodate the additional blood flow. The valves are not able to effectively close, which results in retrograde blood flow and venous hypertension. The venous hypertension, leads to leakage of fluid out of the stretched veins into the tissues, causing deposition of a brownish/red pigment in the gaiter area of the leg. Venous ulceration occurs in the gaiter area in $95 \%$ of cases especially around the malleolar region. Another factor that influences the development of venous leg ulcers is calf muscle pump failure. Calf pump failure arises from paralysis, immobility, sleeping in a chair with legs dependent for long periods of time, and fixed ankle joints. The calf muscle, through contraction and relaxation, aids in the flow of blood back to the heart through the veins. Failure of this mechanism causes stasis of blood and increased venous pressure [1].

Matrix rhythm therapy: According to Dr. Ulrich Randoll Matrix-Rhythm-Therapy is a method to maintain the body's good health (prevention) and to support the healing of muscularskeletal problems, post-operatively as well as rehabilitative. Normal cells are rhythmically vibrating between $8-12 \mathrm{~Hz}$. When any cell is injured or suffering from any injury it's oscillations decreases leading to obstruction in the healing process. Matrix-Rhythm-Therapy is known to delivers physiological rhythmic oscillations between 8-12 Hz that Synchronizes with internal body rhythm and helps in the healing process at microcellular level Matrix reactivates the cell metabolism and normalizes the physiological process by depth-effective rhythmical phase synchronous magneto mechanical oscillations. In this process the cells are stimulated and the entire tissue is rhythmically resynchronized. Matrix basically works and improves the tissue extensibility, and also the circulation. The contracted areas of the musculature will be inductively relaxed by increased circulation which increases oxygenated blood followed by ATP synthesis and dissolution of the tension. Matrix Rhythm Therapy was extensively used in Orthopedic, Neurological and vascular conditions [2-5].

However, we found no previous study on the effects of matrix rhythm therapy in patients with Venous Ulcer. The aim of the study is to evaluate the effectiveness of Matrix Rhythm Therapy for venous ulcer.

\section{CASE PRESENTATION}

A 82 years old male patient reported with venous ulcer along the right lower limb along the lateral side of leg above the malleoli. He is non-diabetic and a known case of hypertension on medication. He was suffering with this complaint for past 4+years, he was initially treated with dressing and medications but didn't give good result. He was continuing dressing for past these years which reduced his life style and made his mobility less. Then he was referred to our center for further management.

As the patient is explained and taken for this study, so he was advised not to take any other forms of medical treatment in treating this ulcer except his regular hypertensive medications alone.

He was advised to stop doing wet dressing and advised to go with dry dressing only as I want to keep it on single mode of treatment and see the effectiveness of matrix rhythm therapy (MaRhyThe) without medications. Patients informed concern was signed and treatment was started.

\section{CLINICAL FINDINGS}

Pain assessment: Visual analogue scale was used to assess pain. It was $7 / 10$ at rest and 8/ 10 while walking.

Wound examination: wound size is length $8 \mathrm{~cm}$ and breadth $7 \mathrm{~cm}$ just $8 \mathrm{~cm}$ above lateral malleoli of right ankle joint.

\section{THERAPEUTIC INTERVENTION}

Patient was made to lie in prone position, treatment area was Para spinal, Gluteal region, Hamstrings, Calf and around the wound and sole of the foot. Treatments areas are nicely powdered with normal talcum powder to avoid 
friction between the skin and the resonator of Matrix Mobil. The Matrix Mobil is a rod shaped with a spiral-shaped vibration head called resonator that vibrates in the physiological range of 8 to $12 \mathrm{~Hz}$. The devices generate a vibratory space-time pattern to which the body tissues can orient themselves in returning to their healthy vibratory mode. The device utilizes a combination of mechanical vibrations together with the oscillating electromagnetic field induced by permanent magnets mounted in the resonator. The application of Matrix Mobil was in a longitudinal stroking manner by pushing the probe of the device into the muscles.

\section{'FOLLOW-UP AND OUTCOMES:}

Outcome measures were recorded in terms of size of the wound healing and VAS for pain. Figure 1 and Figure 2 shows the appearance of wound before and after intervention of Matrix Rhythm Therapy.

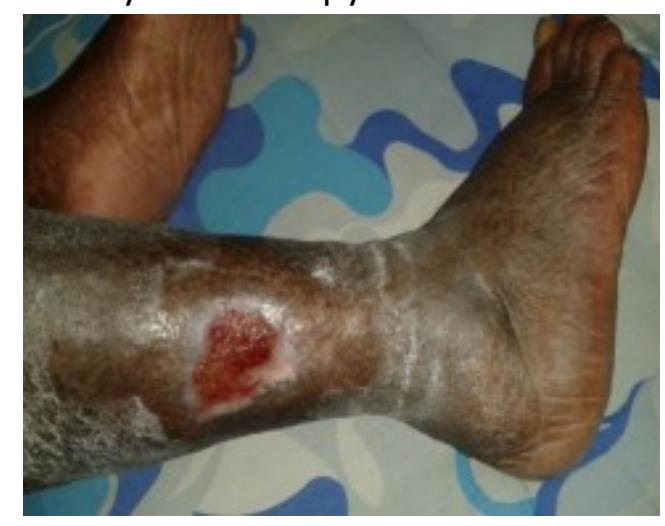

Fig. 1: PRE-Treatment

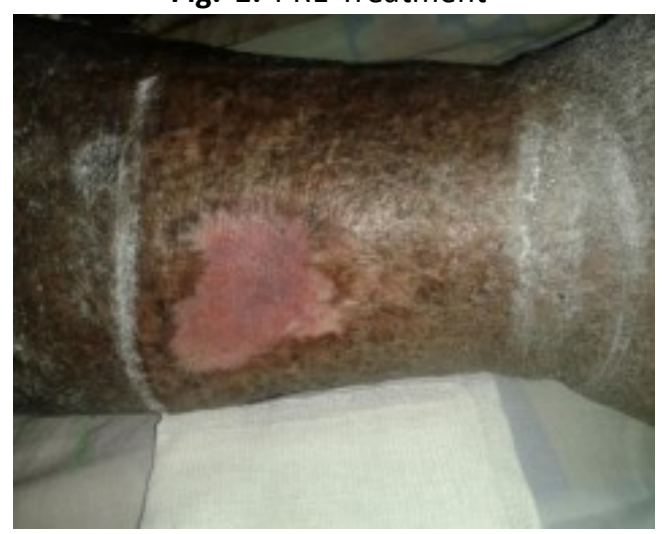

Fig. 2: POST Treatment

\section{DISCUSSION}

The present study was conducted to find the effectiveness of MaRhyThe in healing of Venous Ulcer. There are previous study supporting matrix rhythm therapy (MaRhyThe) in wound healing but it was used with combination of PEMF (pulsed Electromagnetic therapy) and Low-Level laser. This study focused only on application of MaRhyThe in healing of venous ulcer. In earlier studies it found out that vibration is used in the management of wound healing. Using vibration, it produces stimulus which helps in increase in angiogenesis, increase in formulation of granulation tissues which promotes the accumulation of macrophages. Increased macrophages lead to faster wound healing / Closure forming a healthy re-epithelialization. It was found that there is decrease in blood glucose levels, decrease in number of neutrophil cells and decrease in inflammation around the wound. As the inflammation is reduced microcirculation in and around the wound is improved which facilitates the formulation of granulation tissues [4].

In the above study, the frequency of vibrations applied was $35-45 \mathrm{~Hz}$ which is on the higher side to the physiological oscillation/vibrations. Though one of a study has shown effects of vibration in blood flow in healthy inactive subjects showed that vibrations are responsible for increase in blood supply but there are limited studies to support in for healing of venous ulcers.

In our study wound healing is accelerated possibly due to cellular effect of vibrations produced by the application of Matrix Rhythm Therapy (MaRhyThe). As the basic principle behind matrix rhythm therapy (MaRhyThe) is to generate a vibratory space-time pattern to which the body tissues can orient themselves in returning to their healthy or Physiological vibratory range of $8-12 \mathrm{~Hz}$. So, the normal rhythmic vibrations is restored to regain cells function inside and its surrounding namely the extra cellular matrix [5].

In another study they have said application of matrix rhythm therapy (MaRhyThe) has improved circulation for athletes. In that study they have compared with conventional massage and said effect of matrix rhythm therapy (MaRhyThe) is found better than conventional massage. They concluded that, matrix rhythm therapy (MaRhyThe) leads to increase in circulation through compression 
effect and soft tissue mobilization along with contraction of muscles produced by stimulation of tonic vibration reflex [6].

In another study it has proven to improve the microcirculation in tissues which in turn helps in increasing the temperature at the treated tissues. Heating increases the flexibility of collagen tissues and the improved blood flow results in the reduction of joint stiffness and muscle spasm, which helps in improving the flexibility of the muscles and improve in blood circulation around the affected area.

In another study it said, the combined mechanical magnetic waves of the Matrix Mobil $^{\circledR}$ strengthens the natural frequencies of the body, normalize the oscillation spectrum of the skeletal musculature, and as a result also the overall microcirculation. The asymmetric tissue pressure stimulates a pump suction effect and activates the nerve physiologically. This leads to a rhythmic re-adaptation of the entire tissue. Additional healing mechanisms on the molecular level are activated via the indirect piezoelectric properties of the collagens and the extracellular matrix clearance increases which eliminate the pain and improve joint range of motion. Matrix Rhythm Therapy (MaRhyThe) is known to promote the normal Physiologic logistics at the inter and extracellular level by maintaining the normal $\mathrm{pH}$ of the tissues by micro mobilization using the applicator. There are proven evidences that promote improved micro circulation within the tissues which gives the basis of enhanced removal of metabolic waste products, reduction in edema and improving extensibility of soft tissues $[7,8]$.

\section{ACKNOWLEDGEMENTS}

I would like to thank Dr. Varun Naik, Asst. Professor, KLE University's Institute of Physiotherapy, Belagavi, Karnataka, India. I thank my patient for taking concern in helping in this study by signing the consent.

Informed consent: Was duly obtained from subject regarding recorrding and publication of data.

\section{Source of funding: Nil}

\section{Conflicts of interest: None}

\section{REFERENCES}

[1]. Venous leg ulcers: Pathophysiology and Classification Biju Vasudevan, Indian Dermatol Online J. 2014 Jul-Sep; 5(3): 366-370. PMCID: PMC4144244

[2]. The Matrix Concept in Practice - Dr. Randoll Institut - Gemeinnützige Gesellschaft für Matrix Forschung und -Lehre mbH [Internet]. [20.04.2019]. Available from: https://www.dr-randoll institut.de/en/matrix-konzept-inder-praxis.

[3]. Bhatikar K. Effect of Matrix Rhythm Therapy in B/ L Adductor Muscle Tightness in Pediatric Cerebral Palsy: A Case Report. Journal of Palliative Care \& Medicine. 2019;09.

[4]. http://marhythe.in/

[5]. https://www.dr-randoll-institut.de/en/so-wirktdiematrix-rhythmus-therapie-marhythe/

[6]. Ulrich G. Randoll, Friedrich F. Hennig. MatrixRhythmTherapy Cell-Biological Basics, Theory and Practice. J PT Zeitschrift Fur Physiotherapeuten 2009;61.

[7]. Venous leg ulcers: Pathophysiology and Classification Biju Vasudevan, Indian Dermatol Online J. 2014 Jul-Sep; 5(3): 366-370.

[8]. Juniperpublishers.com. 2019 [cited 8 October 2019]. Available from: https:// juniperpublishers.com/jyp/pdf/ JYP.MS.ID.555696.pdf

[9]. Taspinar F, Aslan U, Sabir N, Cavlak U. Implementation of Matrix Rhythm Therapy and Conventional Massage in Young Females and Comparison of Their Acute Effects on Circulation. The Journal of Alternative and Complementary Medicine. 2013;19(10):826-832.

[10]. Naik V, Singh M. Effects of matrix rhythm therapy (MaRhyThe) in plantar fasciitis -An experimental study. Indian J Phys Ther Res 2019; 1:105-109.

[11]. Randoll U. The matrix concept. 1st Edn Munich: SZ Publishing Support 2014.

How to cite this article: Harish Kumar Rajendran. Effect of Matrix Rhythm Therapy in Venous Ulcer Healing: A case report. Int J Physiother Res 2021;9(5):4040-4043. DOI: $10.16965 /$ ijpr.2021.187 